\title{
Needle Entry Angle to Prevent Carotid Sheath Injury for Fluoroscopy-Guided Cervical Transforaminal Epidural Steroid Injection
}

\author{
Jaewoo Choi, $\mathrm{MD}^{1}$, Doo Hoe Ha, $\mathrm{MD}^{2}$, Shinyoung Kwon, $\mathrm{MD}^{1}$, Youngsu Jung, $\mathrm{MD}^{1}$, \\ Junghoon Yu, MD ${ }^{1}$, MinYoung Kim, MD, $\mathrm{PhD}^{1}$, Kyunghoon Min, $\mathrm{MD}^{1}$ \\ Departments of ${ }^{1}$ Rehabilitation Medicine and ${ }^{2}$ Radiology, CHA Bundang Medical Center, \\ CHA University School of Medicine, Seongnam, Korea
}

Objective To suggest rotation angles of fluoroscopy that can bypass the carotid sheath according to vertebral levels for cervical transforaminal epidural steroid injection (TFESI).

Methods Patients who underwent cervical spine magnetic resonance imaging (MRI) from January 2009 to October 2017 were analyzed. In axial sections of cervical spine MRI, three angles to the vertical line ( $\alpha$, angle not to insult carotid sheath; $\beta$, angle for the conventional TFESI; $\gamma$, angle not to penetrate carotid artery) were measured.

Results Alpha $(\alpha)$ angles tended to increase for upper cervical levels $\left(53.3^{\circ}\right.$ in C6-7, $65.2^{\circ}$ in $\mathrm{C} 5-6,75.3^{\circ}$ in $\mathrm{C} 4-5$, $82.3^{\circ}$ in C3-4). Beta ( $\beta$ ) angles for conventional TFESI showed a constant value of $45^{\circ}$ to $47^{\circ}\left(47.5^{\circ}\right.$ in $C 6-7,47.4^{\circ}$ in C5-6, 45.7 in C4-5, 45.0 in C3-4). Gamma $(\gamma)$ angles increased at higher cervical levels as did $\alpha$ angles $\left(25.2^{\circ}\right.$ in $\mathrm{C} 6-7,33.6^{\circ}$ in $\mathrm{C} 5-6,43.0^{\circ}$ in $\mathrm{C} 4-5,56.2^{\circ}$ in $\left.\mathrm{C} 3-4\right)$.

Conclusion The risk of causing injury by penetrating major vessels in the carotid sheath tends to increase at upper cervical levels. Therefore, prior to cervical TFESI, measuring the angle is necessary to avoid carotid vessels in the axial section of CT or MRI, thus contributing to a safer procedure.

Keywords Injections, Epidural, Fluoroscopy, Vascular system injuries, Jugular veins, Carotid arteries

\section{INTRODUCTION}

For the management of cervical radicular pain, epidural steroid injection (ESI) can be performed through the interlaminar or transforaminal approach [1]. Cervical radicular pain can develop following irritation and/or injury of a cervical spinal nerve that induces inflammation $[2,3]$. ESI can carry steroids and anesthetics within the

Received June 1, 2018; Accepted July 26, 2018

Corresponding author: Kyunghoon Min

Department of Rehabilitation Medicine, CHA Bungdang Medical Center, CHA University School of Medicine, 59 Yatap-ro, Bundang-gu, Seongnam 13496, Korea. Tel: +82-31-780-1892, Fax: +82-31-780-3449, E-mail: minkhrm@gmail.com

ORCID: Jaewoo Choi (http://orcid.org/0000-0002-4673-0477); Doo Hoe Ha (http://orcid.org/0000-0003-0744-5697); Shinyoung Kwon (http://orcid. org/0000-0002-6888-8064); Youngsu Jung (http://orcid.org/0000-0001-8173-736X); Junghoon Yu (http://orcid.org/0000-0001-6039-5364); MinYoung Kim (http://orcid.org/0000-0001-5481-2985); Kyunghoon Min (http://orcid.org/0000-0003-3357-9795).

(c) This is an open-access article distributed under the terms of the Creative Commons Attribution Non-Commercial License (http://creativecommons.org/ licenses/by-nc/4.0) which permits unrestricted noncommercial use, distribution, and reproduction in any medium, provided the original work is properly cited. Copyright ( 2018 by Korean Academy of Rehabilitation Medicine 
epidural space to reduce inflammation and nociceptive signaling [4]. In systemic reviews, interlaminar ESI (ILESI) and transforaminal ESI (TFESI) have been shown to have some effects of pain relief for cervical radicular pain $[5,6]$.

As is the case with other needle-based interventions, procedure-related complications can occur following ESI, such as vasovagal reactions, increased pain, and allergic reactions [7]. More serious adverse events such as neurologic damage related to ESI can also happen, although these are rare. TFESI is associated with more risks of the spinal cord or brain infarction, because the needle targets the neural foramen in the vicinity of the vertebral and radiculomedullary arteries [6]. The intended needle placement during ILESI is the dorsal epidural space, which increases the chance of dura puncture or epidural hematoma [8]. The choice of which technique to use should be decided in consideration of the risks and benefits for each patient [9]. In the cervical spine, ILESI is suggested as the initial approach based on the purported increased safety of the technique [10]. However, the ventral spread of the injectate with cervical ILESI is only $28 \%$ [11]. For that reason, some physicians favor TFESI, because the delivery of the injectate is directly around the inflamed nerve root and dorsal root ganglion [12].

During cervical TFESI, the needle should be guided to the posterior aspect of neural foramen under fluoroscopy (C-arm) so as to prevent injury to the vertebral artery $[13,14]$. The C-arm should be rotated to the symptomatic side by $45^{\circ}$ to $60^{\circ}$ in order to maximize the size of the foramen [12]. Finally, after an optimal trajectory view can be seen by tilting to the posterior side, a needle approaches the superior articular process in the direction of the posterior aspect of the intervertebral foramen $[15,16]$. In CT analysis, the required rotation angle is approximately $50^{\circ}$ [17].

Major vessels of the carotid sheath are also located around the cervical roots. In a rat study, direct injection of particulate steroids into the carotid artery caused brain lesions [18]. If hematoma occurs due to vessel injury of the carotid artery, it might cause neck pain, headache, facial pain, miosis, and ptosis, similar to dissection of the carotid artery [19]. Eventually, it causes infarctions and leaves severe sequela of cerebral or retinal ischemic symptoms [20-22]. Fluoroscopic guidance with contrast provides proper information about epidural space and target tissue. However, it is possible to misplace the tip of injection in up to $30 \%$ of cases, because there is a limitation in directly confirming the vascular structure [23]. Hence, there is a risk of injuring the carotid sheath during cervical TFESI [24]. To our knowledge, no studies on needle entry angle mainly focusing on the carotid sheath have been reported yet.

The angle for bypassing the carotid sheath might serve as another safety parameter for physicians in addition to the conventional C-arm adjustment angle. The aim of this study was to suggest rotation C-arm angles that could prevent injury to the carotid sheath according to vertebral levels for cervical TFESI.

\section{MATERIALS AND METHODS}

This study is a retrospective study using chart review. It was approved by the Institutional Review Board of CHA Bundang Medical Center (No. 2017-11-038).

\section{Subjects}

Patients who underwent cervical spine magnetic resonance imaging (MRI) from January 2009 to October 2017 were included. The inclusion criteria were: (1) age of 18 years or older and (2) patients whose MRI scans were available. Patients were excluded if they had any cervical fractures or previous vertebral fusion surgery of more than two levels.

\section{Measurement}

Axial sections of cervical spine MRI were analyzed. Both sides of four levels of bilateral neural foramen from C3-4 to C6-7, where cervical radicular pains affected the roots by cervical disc and osseoligamentous disorders were prevalent, were selected $[25,26]$. The axial section was defined as the plane of the upper third of the superior articular process and traversing intervertebral disc. The axial section optimally shows the position of the needle tip when performing TFESI $[17,27]$. The first line was drawn from the lateral margin of the carotid sheath border to the mid-point of the superior articular process. The second line was drawn parallel to the ventral lamina; this is the conventional route into the neural foramen [17]. The third line was drawn from the lateral margin of the carotid artery in the sheath to the mid-point of the superior articular process in order to discriminate angles so as to avoid the internal jugular vein (IJV) and carotid artery 
(CA) (Fig. 1). The angles between the vertical line passing through the spinous process and each line were measured ( $\alpha$ is angle between the first and vertical lines not to injure the carotid sheath; $\beta$ is angle between the second and vertical lines for the conventional TFESI; $\gamma$ is angle between the third and vertical lines not to penetrate CA) [28]. The distance from the entry of the skin surface to the posterior tubercles for the first line ( $\alpha$ angle) was also measured. All operations were performed using a commercially available picture archiving software, Maroview version 5.4 (Marotech Inc., Seoul, Korea). The needle entry line was drawn along the $\beta$ angle and the frequency of the conventional needle entry angle penetrating the vessel was recorded after verifying that the line had passed the CA and IJV.

\section{Review of clinical data}

A chart review was performed to collect each patient's age, sex, height, and weight at the time of MRI. Body mass index (BMI) was calculated as body weight divided by the square of height.

\section{Statistics}

Descriptive analyses were performed and confidence intervals were calculated using Student t-test for continuous variables. One-way ANOVA was performed in order

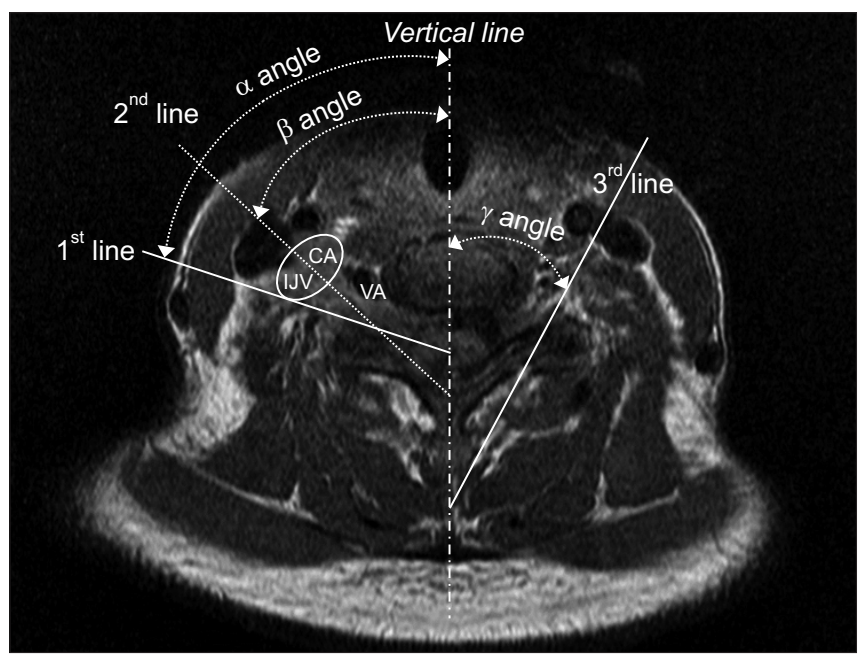

Fig. 1. Measurement of needle entry angle (vertical line). CA, carotid artery; IJV, internal jugular vein; VA, vertebral artery; $1^{\text {st }}$ line, needle entry line to avoid carotid sheath ( $\alpha$ angle); $2^{\text {nd }}$ line, needle entry line along the posterior wall in the neural foramen ( $\beta$ angle); $3^{\text {rd }}$ line, needle entry line to avoid carotid artery in the sheath ( $\gamma$ angle). to determine if there was any difference between angles. Correlations among demographical factors, $\alpha / \beta / \gamma$ angles, and distance were analyzed using Pearson correlation tests. Intraclass correlation coefficients (ICCs) were calculated as $\operatorname{ICC}(2,1)$ for inter-rater and $\operatorname{ICC}(1,1)$ for intrarater reliability. All statistical analyses were performed using SPSS version 21.0 (IBM Inc., Armonk, NY, USA).

\section{RESULTS}

Of a total of 125 patients who met the inclusion criteria, 84 were ultimately analyzed after excluding those who met the exclusion criteria. The participants' demographic data are summarized in Table 1 . The mean age of these patients ( 48 males and 36 females) was 47.9 years. The radiologic pathologies of these patients are shown in Table 2.

In terms of inter-rater and intra-rater reliability, the ICC values of angles and distances at each level were higher than $0.90(p<0.001)$ [29]. Fig. 2 shows the average $\alpha, \beta$, and $\gamma$ angles measured for each level. Alpha $(\alpha)$ angles had a tendency to increase for upper cervical levels. In addition, the $\alpha$ angles were significantly (one-way ANOVA test, $\mathrm{p}<0.01$ ) different between two consecutive

Table 1. Demographic data $(\mathrm{n}=84)$

\begin{tabular}{lc}
\hline \multicolumn{1}{c}{ Parameter } & Value \\
\hline Age $(\mathrm{yr})$ & $47.9(19-80)$ \\
Sex & \\
$\quad$ Male & $48(57.1)$ \\
\hline Female & $36(42.9)$ \\
Height $(\mathrm{cm})$ & $165.2(148.3-183.0)$ \\
Weight $(\mathrm{kg})$ & $63.3(40.0-97.3)$ \\
BMI $\left(\mathrm{kg} / \mathrm{m}^{2}\right)$ & $23.1(17.1-32.9)$ \\
History of fusion surgery $(<2$ levels $)$ & $4(4)$ \\
\hline
\end{tabular}

Values are presented as mean \pm standard deviation or number (\%).

BMI, body mass index.

Table 2. Radiologic pathologies

\begin{tabular}{lcccc}
\hline \multicolumn{1}{c}{ Diagnosis } & C3-4 & C4-5 & C5-6 & C6-7 \\
\hline $\begin{array}{l}\text { Herniated disc } \\
\text { or stenosis }\end{array}$ & $26(30.9)$ & $30(35.6)$ & $37(43.9)$ & $28(33.3)$ \\
Myelopathy & $9(10.7)$ & $7(8.3)$ & $8(9.5)$ & $8(9.5)$ \\
Normal & $49(58.3)$ & $47(55.9)$ & $39(46.4)$ & $48(57.1)$ \\
\hline
\end{tabular}

Values are presented as number (\%). 


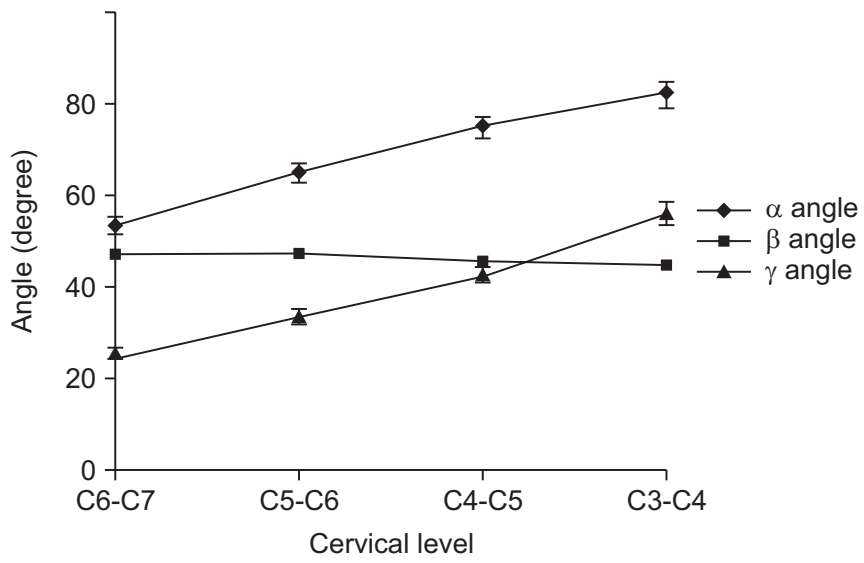

\begin{tabular}{c|l|llll}
\hline \multicolumn{2}{l}{ Total $(\mathrm{n}=168)$} & \multicolumn{1}{l}{ C6-C7 } & C5-C6 & C4-C5 & C3-C4 \\
\hline \multirow{3}{*}{$\alpha$ angle } & AVR & 53.3 & 65.2 & 75.3 & 82.3 \\
& STD & 12.4 & 13.7 & 15.8 & 18.6 \\
& 95\% Cl & $51.4-55.2$ & $63.1-67.4$ & $72.8-77.8$ & $79.3-85.3$ \\
\hline \multirow{3}{*}{$\beta$ angle } & AVR & 47.5 & 47.4 & 45.7 & 45.0 \\
& STD & 6.5 & 5.6 & 5.6 & 5.3 \\
& 95\% Cl & $46.5-48.6$ & $46.6-48.2$ & $44.9-46.5$ & $44.1-45.8$ \\
\hline \multirow{3}{*}{$\gamma$ angle } & AVR & 25.2 & 33.6 & 43.0 & 56.2 \\
& STD & 8.9 & 11.4 & 12.9 & 16.2 \\
& 95\% Cl & $23.9-26.6$ & $31.8-35.4$ & $41.0-45.0$ & $53.7-58.8$ \\
\hline
\end{tabular}

Fig. 2. Measured values of $\alpha, \beta$, and $\gamma$ angles. $\alpha$ angle, needle entry angle to avoid carotid sheath from the vertical line; $\beta$ angle, needle entry angle to conventional TFESI approach from the vertical line; $\gamma$ angle, needle entry angle to avoid carotid artery from the vertical line; AVR, average; STD, standard deviation; CI, confidence interval; TFESI, transforaminal epidural steroid injection.

cervical vertebral levels. Beta ( $\beta$ ) angles for conventional TFESI constantly showed a value between $45^{\circ}$ to $47^{\circ}$; they slightly decreased at higher levels. There was no significant difference between C3-4 and C4-5 or between C5-6 and C6-7. However, there was a significant difference between C4-5 and C5-6 ( $\mathrm{p}<0.01)$. Gamma $(\gamma)$ angles also increased at higher cervical levels. In addition, they were significantly different between cervical levels (one-way ANOVA test, $\mathrm{p}<0.01)$. Conventional needle entry angle line ( $\beta$ angle) passed most of the carotid sheath at the measured cervical level, especially for the carotid artery. The frequency was higher in the upper cervical level (Table 3). There were significant correlations for several values (Table 4). Among them, the correlation coefficients between BMI and distances for $\alpha$ angle were higher at each level.
Table 3. Frequency of conventional needle entry line ( $\beta$ angle) penetrating the vessel and sheath

\begin{tabular}{cccc}
\hline Level & $\begin{array}{c}\text { Carotid artery } \\
(\mathbf{n}=168)\end{array}$ & $\begin{array}{c}\text { Internal jugular } \\
\text { vein }(\mathbf{n = 1 6 8})\end{array}$ & $\begin{array}{c}\text { Carotid sheath } \\
(\mathbf{n}=168)\end{array}$ \\
\hline C3-4 & $116(69.0)$ & $49(29.1)$ & $165(98.2)$ \\
C4-5 & $64(38.1)$ & $102(62.1)$ & $166(98.8)$ \\
C5-6 & $21(12.5)$ & $136(82.9)$ & $157(93.4)$ \\
C6-7 & $3(1.8)$ & $120(73.1)$ & $123(73.2)$ \\
\hline
\end{tabular}

Values are presented as numbers of lines penetrating each vessel (\%).

We drew a line parallel to lamina directing to superior articular on each side and for cervical disc levels C3-4, C45, C5-6, and C6-7 in 84 MRIs. We evaluated a total of 168 lines per each disc level to see the percentage of vessel (carotid artery, internal jugular vein, carotid sheath) penetration.

\section{DISCUSSION}

In order to minimize the risk of injury to the carotid sheath containing the IJV and CA, C-arm rotation angles were measured and compared with conventional C-arm rotation angles by MRI analysis. The needle entry angles necessary to avoid the carotid sheath at each level ( $\alpha$ angles) as well as angles necessary to avoid the CA ( $\gamma$ angles) were found to increase at higher cervical levels (Figs. $2,3)$. The average value of the needle entry angle along the posterior wall of the neural foramen ( $\beta$ angle) was relatively consistent. It was not different from the average of $48.7^{\circ}$ for the C3-4 to $\mathrm{C} 7-\mathrm{T} 1$ levels reported in a previous article [17]. The frequency of CA penetration of conventional needle entry line was higher in the upper cervical level.

The presence of larger $\alpha$ angles than $\beta$ angles suggests that the needle insertion angle should be in a shallower slope, requiring more $\mathrm{C}$-arm rotation angle than the conventional rotation angle so as to avoid injuring the carotid sheath. Since $\alpha$ angles are larger at higher levels, the chance of $\alpha$ angles exceeding $\beta$ angles becomes higher. In other words, the needle is more likely to penetrate the carotid sheath if only $\beta$ angle is considered, as is the case in conventional cervical TFESI at upper cervical levels. This finding is thought to be consistent with the anatomic relationship in three-dimensional view [30]. The common carotid artery (CCA) contained in the carotid sheath is divided into internal and external CAs around the C4 level. Internal CA travels the deeper pathway in the ca- 
Table 4. Demographic factors and correlations among demographical factors, $\alpha / \beta / \gamma$ angles, and distance

\begin{tabular}{|c|c|c|c|c|c|c|c|c|}
\hline \multirow{2}{*}{ Correlation } & \multicolumn{2}{|c|}{ Age } & \multicolumn{2}{|c|}{ Height } & \multicolumn{2}{|c|}{ Weight } & \multicolumn{2}{|c|}{ BMI } \\
\hline & $\mathbf{r}$ & p-value & $\mathbf{r}$ & p-value & $\mathbf{r}$ & p-value & $\mathbf{r}$ & p-value \\
\hline C3-4 $\alpha$ angle & 0.130 & 0.096 & -0.047 & 0.545 & -0.012 & 0.879 & -0.023 & 0.763 \\
\hline C3-4 $\beta$ angle & 0.011 & 0.890 & 0.056 & 0.467 & -0.054 & 0.486 & -0.106 & 0.173 \\
\hline C3-4 $\gamma$ angle & 0.138 & 0.074 & -0.106 & 0.172 & -0.122 & 0.115 & 0.047 & 0.548 \\
\hline C3-4 distance & 0.203 & $0.008^{*}$ & 0.247 & $0.001^{*}$ & 0.580 & $0.000^{*}$ & 0.578 & $0.000^{*}$ \\
\hline C4-5 $\alpha$ angle & 0.228 & $0.003^{*}$ & -0.092 & 0.238 & -0.016 & 0.833 & 0.051 & 0.509 \\
\hline C4-5 $\beta$ angle & -0.034 & 0.660 & -0.117 & 0.131 & -0.042 & 0.590 & 0.029 & 0.714 \\
\hline C4-5 $\gamma$ angle & 0.109 & 0.161 & -0.053 & 0.492 & 0.040 & 0.604 & 0.073 & 0.348 \\
\hline C4-5 distance & 0.247 & $0.001^{*}$ & 0.244 & $0.001^{*}$ & 0.443 & $0.000^{*}$ & 0.402 & $0.000^{*}$ \\
\hline C5-6 $\alpha$ angle & 0.096 & 0.215 & 0.138 & 0.075 & 0.128 & 0.098 & 0.071 & 0.361 \\
\hline C5-6 $\beta$ angle & -0.042 & 0.585 & 0.038 & 0.628 & 0.095 & 0.220 & 0.099 & 0.201 \\
\hline C5-6 $\gamma$ angle & 0.055 & 0.479 & 0.002 & 0.981 & 0.135 & 0.081 & 0.101 & 0.193 \\
\hline C5-6 distance & 0.139 & 0.072 & 0.220 & $0.004^{*}$ & 0.519 & $0.000^{*}$ & 0.521 & $0.000^{*}$ \\
\hline C6-7 $\alpha$ angle & 0.166 & 0.032 & 0.167 & 0.031 & 0.212 & 0.006 & 0.152 & 0.050 \\
\hline C6-7 $\beta$ angle & -0.042 & 0.587 & 0.075 & 0.334 & 0.138 & 0.075 & 0.127 & 0.102 \\
\hline C6-7 $\gamma$ angle & -0.004 & 0.962 & 0.039 & 0.615 & 0.229 & 0.003 & 0.097 & 0.209 \\
\hline C6-7 distance & 0.182 & 0.018 & 0.146 & 0.059 & 0.399 & $0.000^{*}$ & 0.424 & $0.000^{*}$ \\
\hline
\end{tabular}

BMI, body mass index.

${ }^{*} \mathrm{p}<0.05$ by Pearson correlation test.
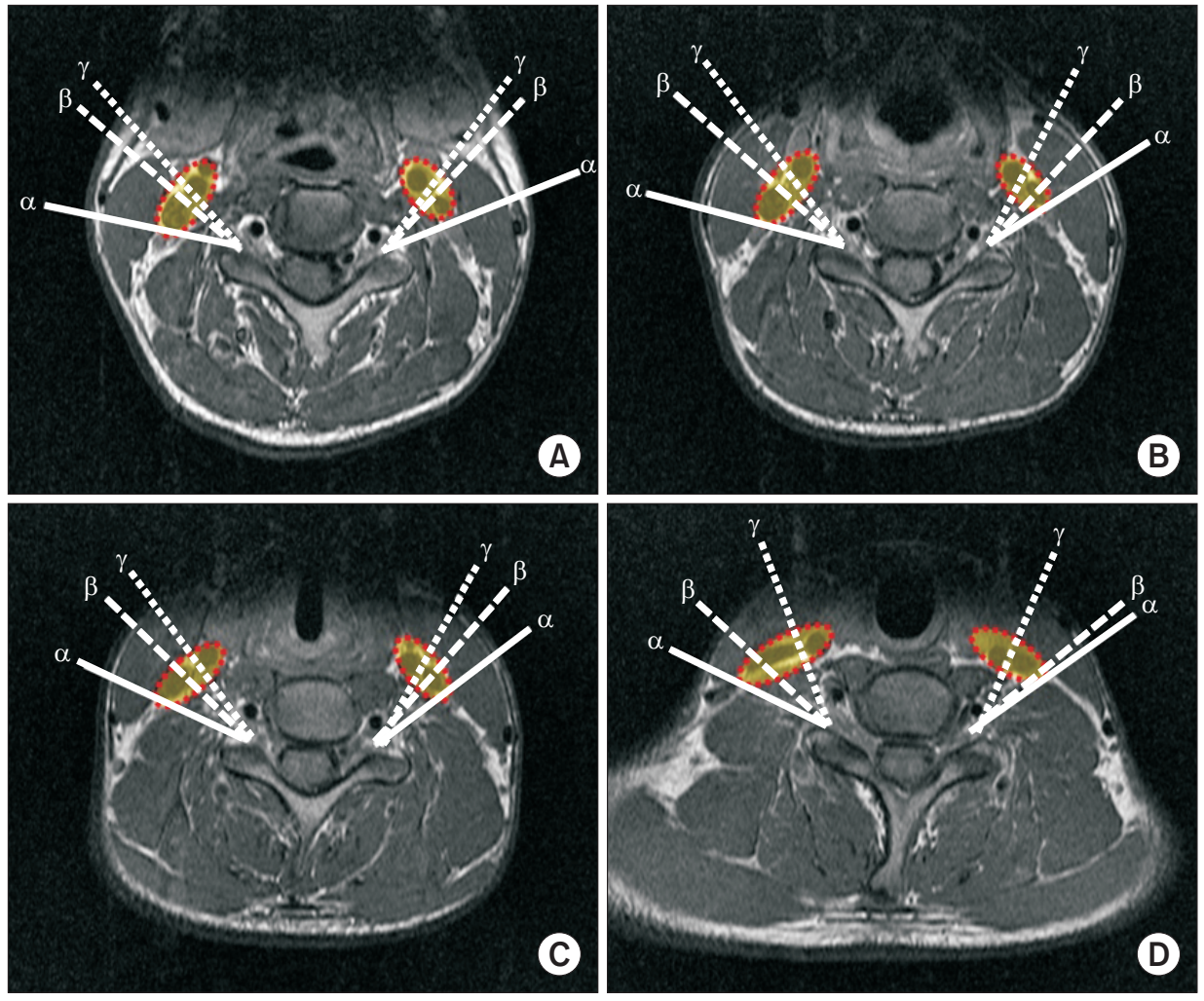

Fig. 3. Magnetic resonance images of $\alpha, \beta$, and $\gamma$ angles at each level. (A) C3-4, (B) C4-5, (C) C5-6, and (D) C6-7 levels. $\alpha$ line, $\alpha$ angle to avoid carotid sheath; $\beta$ line, $\beta$ angle for conventional TFESI approach; $\gamma$ line, $\gamma$ angle to avoid carotid artery; red dashed line, carotid sheath including carotid artery and internal jugular vein; TFESI, transforaminal epidural steroid injection. 


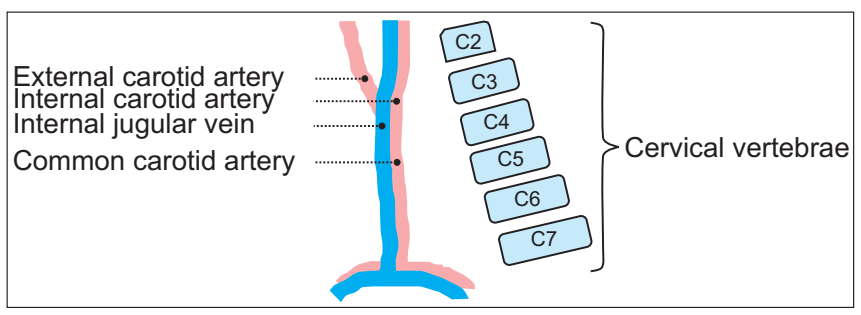

Fig. 4. Schematic illustrations of internal jugular vein, carotid artery, and lordotic cervical curvature. Dashed lines indicate external, internal, common carotid artery, and internal jugular vein. Consecutive squares are arrangement of schematic cervical vertebrae.

rotid sheath. IJV moves to the lateral side of the CA up to the C3-4 level. The margin of the carotid sheath is mostly determined by IJV [31-33]. Considering the anterior to posterior passage of the carotid sheath from the aortic arch to the skull base as well as the lordotic curvature of the cervical vertebrae, they become closer at higher cervical levels (Fig. 4).

In the carotid sheath, IJV is located lateral to the CA in about $70 \%$ of cases [34]. The needle approaches from the lateral to the medial side during cervical TFESI, and the penetration of IJV might be a trivial issue. However, in $30 \%$ of cases, anterior or even medial positions of IJV to the CA are reported [34]. Avoiding injury of CA is critical for safe interventions. In addition, the $\gamma$ angle avoiding injury to the CA, similar to the tendency of the $\alpha$ angle, was found to be larger than the $\beta$ angle at upper cervical level. The frequency of CA penetration injury increased at higher cervical levels (Fig. 2, Table 3). Therefore, for upper cervical levels, an injection route considering the position of the CA through cervical MRI analysis is required.

In previous literature, Nishio [35] proposed that preprocedural evaluation should include analysis of patient's MRI so as to confirm the locations of certain structures such as neural foramen and vertebral and carotid artery. However, the proposal was at the level of suggestion without statistical analysis. In 2017, Karm et al. [28] suggested a new injection route parallel to the midpoint of the superior articular process's ventral border with lower frequency of penetrating vertebral and carotid arteries and IJV in comparison to the conventional injection route. The angles of the new injection route ranged from $66^{\circ}$ to $72^{\circ}$, which were greater than $48.7^{\circ}$, the angle of the conventional injection route $[17,28]$. Interestingly, the penetrating frequency of IJV and CCA at C5-6 was higher than that of $\mathrm{C} 7-\mathrm{T} 1$ with the new injection route [28]. Although the study did not describe tendency, it was consistent with our result in that the likelihood of major vessel injuries increased at higher cervical levels. Otherwise, the frequency of penetrating CCA by $\beta$ angle (conventional TFESI route) was similar, although that of IJV was higher compared to that in a previous study [28]. This discrepancy might be due to the fact that different subjects were analyzed. Overall, some results of that study [28] support the results of the present study. That study focused on proposing an intuitive needle entry line for clinical application [28]. However, in the present study, the needle entry angle showed that the upper cervical level had a higher injury rate of the CA. Thus, we suggested a value that could be used as reference.

This study has several limitations. First, this study employed a retrospective design. Although exclusion criteria were applied, some heterogeneity of subjects existed because the patient population was not completely controlled. Second, the sample size was small for general application. Third, the axial section of MRI image might not be exactly identical in $\mathrm{C}$-arm view.

In conclusion, carotid sheath injury may occur if only $\beta$ angles are considered to maximize neural foramen during conventional cervical TFESI using C-arm. The risk of major vessel penetrating injury was found to be higher at upper cervical levels. Therefore, prior to cervical TFESI, it is recommended to measure the angle so as to avoid carotid vessels in an axial section of CT or MRI. This might contribute to the development of a safer procedure.

\section{CONFLICT OF INTEREST}

No potential conflict of interest relevant to this article was reported.

\section{REFERENCES}

1. Van Zundert J, Huntoon M, Patijn J, Lataster A, Mekhail N, van Kleef M, et al. 4. Cervical radicular pain. Pain Pract 2010;10:1-17.

2. Rathmell JP, Aprill C, Bogduk N. Cervical transforaminal injection of steroids. Anesthesiology 2004;100: 1595-600.

3. Kang JD, Stefanovic-Racic M, McIntyre LA, Georgescu HI, Evans CH. Toward a biochemical understanding 
of human intervertebral disc degeneration and herniation. Contributions of nitric oxide, interleukins, prostaglandin E2, and matrix metalloproteinases. Spine (Phila Pa 1976) 1997;22:1065-73.

4. House LM, Barrette K, Mattie R, McCormick ZL. Cervical Epidural steroid injection: techniques and evidence. Phys Med Rehabil Clin N Am 2018;29:1-17.

5. Diwan S, Manchikanti L, Benyamin RM, Bryce DA, Geffert S, Hameed H, et al. Effectiveness of cervical epidural injections in the management of chronic neck and upper extremity pain. Pain Physician. 2012; 15:E405-34.

6. Engel A, King W, MacVicar J; Standards Division of the International Spine Intervention Society. The effectiveness and risks of fluoroscopically guided cervical transforaminal injections of steroids: a systematic review with comprehensive analysis of the published data. Pain Med 2014;15:386-402.

7. El-Yahchouchi CA, Plastaras CT, Maus TP, Carr CM, McCormick ZL, Geske JR, et al. Adverse event rates associated with transforaminal and interlaminar epidural steroid injections: a multi-institutional study. Pain Med 2016;17:239-49.

8. Huston CW. Cervical epidural steroid injections in the management of cervical radiculitis: interlaminar versus transforaminal: a review. Curr Rev Musculoskelet Med 2009;2:30-42.

9. Manchikanti L, Falco FJ, Benyamin RM, Gharibo CG, Candido KD, Hirsch JA. Epidural steroid injections safety recommendations by the Multi-Society Pain Workgroup (MPW): more regulations without evidence or clarification. Pain Physician 2014;17:E57588.

10. Cohen SP, Bicket MC, Jamison D, Wilkinson I, Rathmell JP. Epidural steroids: a comprehensive, evidencebased review. Reg Anesth Pain Med 2013;38:175-200.

11. Stojanovic MP, Vu TN, Caneris O, Slezak J, Cohen SP, Sang CN. The role of fluoroscopy in cervical epidural steroid injections: an analysis of contrast dispersal patterns. Spine (Phila Pa 1976) 2002;27:509-14.

12. Lee JH, Lee SH. Comparison of clinical efficacy between interlaminar and transforaminal epidural injection in patients with axial pain due to cervical disc herniation. Medicine (Baltimore) 2016;95:e2568.

13. Scanlon GC, Moeller-Bertram T, Romanowsky SM, Wallace MS. Cervical transforaminal epidural steroid injections: more dangerous than we think? Spine (Phila Pa 1976) 2007;32:1249-56.

14. Schneider BJ, Maybin S, Sturos E. Safety and complications of cervical epidural steroid injections. Phys Med Rehabil Clin N Am 2018;29:155-69.

15. Strub WM, Brown TA, Ying J, Hoffmann M, Ernst RJ, Bulas RV. Translaminar cervical epidural steroid injection: short-term results and factors influencing outcome. J Vasc Interv Radiol 2007;18:1151-5.

16. Furman MB, Berkwits L, Cohen I, Goodman B, Kirschner J, Lee TS. et al, Atlas of image-guided spinal procedures. 2nd ed. Philadelphia: Elsevier; 2018. p. 243-9.

17. Chen B, Rispoli L, Stitik TP, Foye PM, Georgy JS. Optimal needle entry angle for cervical transforaminal epidural injections. Pain Physician 2014;17:139-44.

18. Dawley JD, Moeller-Bertram T, Wallace MS, Patel PM. Intra-arterial injection in the rat brain: evaluation of steroids used for transforaminal epidurals. Spine (Phila Pa 1976) 2009;34:1638-43.

19. Schievink WI. Spontaneous dissection of the carotid and vertebral arteries. N Engl J Med 2001;344:898-906.

20. Silbert PL, Mokri B, Schievink WI. Headache and neck pain in spontaneous internal carotid and vertebral artery dissections. Neurology 1995;45:1517-22.

21. Biousse V, D'Anglejan-Chatillon J, Massiou H, Bousser MG. Head pain in non-traumatic carotid artery dissection: a series of 65 patients. Cephalalgia 1994;14:33-6.

22. Biousse V, D'Anglejan-Chatillon J, Touboul PJ, Amarenco P, Bousser MG. Time course of symptoms in extracranial carotid artery dissections: a series of 80 patients. Stroke 1995;26:235-9.

23. Stewart HD, Quinnell RC, Dann N. Epidurography in the management of sciatica. Br J Rheumatol 1987;26: 424-9.

24. Fitzgerald RT, Bartynski WS, Collins HR. Vertebral artery position in the setting of cervical degenerative disease: implications for selective cervical transforaminal epidural injections. Interv Neuroradiol 2013; 19:425-31.

25. Kim HJ, Nemani VM, Piyaskulkaew C, Vargas SR, Riew KD. Cervical radiculopathy: incidence and treatment of 1,420 consecutive cases. Asian Spine J 2016;10:2317.

26. Wilbourn AJ, Aminoff MJ. AAEM minimonograph 32: the electrodiagnostic examination in patients with 
radiculopathies. American Association of Electrodiagnostic Medicine. Muscle Nerve 1998;21:1612-31.

27. Carette S, Fehlings MG. Clinical practice: cervical radiculopathy. N Engl J Med 2005;353:392-9.

28. Karm MH, Park JY, Kim DH, Cho HS, Lee JY, Kwon $\mathrm{K}$, et al. New optimal needle entry angle for cervical transforaminal epidural steroid injections: a retrospective study. Int J Med Sci 2017;14:376-81.

29. Landis JR, Koch GG. The measurement of observer agreement for categorical data. Biometrics 1977;33: 159-74.

30. Batzdorf U, Batzdorff A. Analysis of cervical spine curvature in patients with cervical spondylosis. Neurosurgery 1988;22:827-36.

31. Lo A, Oehley M, Bartlett A, Adams D, Blyth P, Al-Ali S. Anatomical variations of the common carotid artery bifurcation. ANZ J Surg 2006;76:970-2.
32. Shoja MM, Ardalan MR, Tubbs RS, Loukas M, Vahedinia S, Jabbary $\mathrm{R}$, et al. The relationship between the internal jugular vein and common carotid artery in the carotid sheath: the effects of age, gender and side. Ann Anat 2008;190:339-43.

33. Bouthillier A, van Loveren HR, Keller JT. Segments of the internal carotid artery: a new classification. Neurosurgery 1996;38:425-33.

34. Gordon AC, Saliken JC, Johns D, Owen R, Gray RR. US-guided puncture of the internal jugular vein: complications and anatomic considerations. J Vasc Interv Radiol 1998;9:333-8.

35. Nishio I. Cervical transforaminal epidural steroid injections: a proposal for optimizing the preprocedural evaluation with available imaging. Reg Anesth Pain Med 2014;39:546-9. 